\title{
Meu corpo em campo: reflexões e desafios no trabalho etnográfico com imigrantes na Itália
}

Fabiane Cristina Albuquerque

Universidade Estadual de Campinas, Campinas, São Paulo, Brasil

DOI 10.11606/issn.2316-9133.v26i1p309-326

resumo $\mathrm{O}$ objetivo deste artigo consiste em trazer para o debate os desafios em campo enfrentados pelo corpo da pesquisadora, nesse caso, o meu corpo, e todos os desafios encontrados durante a pesquisa etnográfica num contexto bem delimitado: Veronetta, um bairro multiétnico em Verona, na Itália. Questões como gênero e raça, que perpassam tais desafios, se mostraram relevantes para os estudos dessa natureza, como o acesso ou não a determinados lugares, a circulação no próprio bairro, as relações interpessoais e, enfim, o êxito da pesquisa. Esse corpo da pesquisadora, elemento muitas vezes transcurado nas pesquisas, é trazido ao debate como parte importante da epistemologia, o que implica restituir a corporeidade de todo fazer e saber científico.

palavras-chave corpo, pesquisadora, etnografia, imigrante, Itália.

My body on the field: reflections and challenges in the ethnographic work with immigrants in Italy

abstract This article has the objective to debate the challenges in the field faced by the researcher's body, in this case, my body and all the challenges encountered during my ethnographic research in a well-defined context: Veronetta, a multiethnic neighborhood in the city of Verona (Italy). Issues such as gender and race, which permeate these challenges, have proved relevant to studies of this nature, such as access (or not) to certain places, circulation in the neighborhood, interpersonal relationships and, finally, the success of the research. The body of the researcher, an element often overlooked in research, is brought to debate as an important part of the epistemology, which implies restoring the corporeality of all scientific knowledge and doing.

keywords body, researcher, ethnography, immigrant, Italy. 


\section{Introdução}

Dentro do objeto principal de minha pesquisa de mestrado, a imigração e a insegurança (e se os imigrantes incorporam essa representação sobre eles), realizei, entre dezembro de 2015 e abril de 2016, na cidade italiana de Verona, especificamente em um bairro chamado Veronetta, a reflexão acerca do corpo em campo. Esta se deu a partir da leitura de Haraway (1995) e seus apontamentos acerca da tradição científica produzida majoritariamente por homens brancos e ocidentais pretendendo "descorporificar" a ciência e as pesquisas empíricas, tornando os saberes "neutros" e "universais". A desconexão entre corpo e saber, ou mente, produzida por essa tradição se legitimou no campo da "Ciência", condicionando as produções científicas e se perpetuando no tempo. Tanto o olhar do pesquisador quanto o seu "objeto" de estudo também passaram a ser "desprovido de paixões" e sem corpo, por isso "não falho".

Tal questão perpassou toda a minha pesquisa de campo realizada em Veronetta através de encontros, entrevistas e observação participante. Nos cinco meses em que morei no bairro, aluguei um quarto em uma das quatro zonas ${ }^{1}$, por um preço bem popular, mediante uma estrutura da Igreja Católica mediada por freiras brasileiras (com quem já havia trabalhado no Brasil anteriormente, e que atualmente vivem em Verona). Enquanto aluna visitante da Università degli Studi di Verona, tive como professora responsável a antropóloga Rosanna Cima, e logo no primeiro dia em que me apresentei com papéis nas mãos para o acordo entre as duas universidades, enquanto ela me apresentava a sala em que poderia usar nesse período, surgiu um professor de sociologia que, apresentando muita simpatia (éramos da mesma área), disse: "Os brasileiros são muito bem-vindos aqui, muito mesmo. Nós gostamos de brasileiros. Uma vez conheci um brasileiro, negro, e eu o aconselhava a dizer logo de início que ele era do Brasil”. Essa sua fala mostra o quanto a negritude, ou seja, o corpo negro, imigrante, pode ser um problema no contato do dia a dia no país, se não vier acompanhado de um atributo que o qualifique - como, por exemplo, este: "ser também brasileiro".

Assim, quando Haraway (1995) diz que todo saber é corporificado, não se trata de um determinismo biológico, mas de perceber como a construção desses corpos e o lugar que a eles é dado nas sociedades e nas relações condicionam homens e mulheres, então, de forma diferente. Corpo e linguagem estão intrinsecamente ligados na perspectiva de Haraway, e o corpo da pesquisadora - nesse caso o meu - é uma questão a ser considerada a todo o momento, e sobre o qual reflito como parte da metodologia e do campo de pesquisa.

\footnotetext{
${ }^{1} \mathrm{O}$ bairro é dividido geograficamente em quatro zonas. São elas: San Giovanni in Valle, San Paolo, San Stefano e Veronetta centro.
} 
A perspectiva do "saber corporificado" proposta pela autora pode ser verificada durante o trabalho etnográfico com imigrantes, principalmente na maneira de abordá-los, ou como iniciar uma conversa, solicitar uma entrevista e ter acesso ou não a locais que eles(as) frequentam. Minha presença ali me mostrava o tempo todo que eu tinha um corpo, corpo esse marcado por estereótipos, tais como o de mulher brasileira, negra, latino-americana ${ }^{2}$. Esse corpo de mulher não me permitia, por exemplo, frequentar alguns lugares sozinha, pois sofri diversos assédios por parte dos homens logo no início das minhas caminhadas pelo bairro.

Nos primeiros dias, a fim de percorrer algumas zonas do bairro Veronetta apontadas pelos próprios imigrantes como de "má fama" e "perigosas" videi uma amiga também brasileira e, em uma determinada noite, em um bar, dois senhores italianos (na faixa etária entre 60 e 70 anos) começaram a nos olhar fixamente. Percebendo que nos confundiam com prostitutas, resolvemos deixar o local, mas enquanto nos dirigíamos a outro ponto de Veronetta, vimos que estávamos sendo seguidas por eles, que logo nos dirigiram algumas palavras. Porém, quando ameacei chamar a polícia, se afastaram definitivamente. Ao contar esse fato a alguns imigrantes brasileiros do sexo masculino, tive a seguinte explicação para o ocorrido: "Mas você sabe onde está? Aqui vem muita mulher fácil, não é culpa do homem” (Marcio, brasileiro).

Não poder frequentar alguns lugares com meu corpo me preocupava, uma vez que tal impedimento trazia sérias dificuldades ao desenvolvimento da pesquisa. Foi quando, em uma associação do bairro, conheci Enrico, um senhor italiano de quase 60 anos. Expus-lhe minhas dificuldades e ele disse que conhecia muitos proprietários de lojas no bairro, em sua maioria imigrantes, e que há anos frequentava as áreas mais estigmatizadas. Vendo o meu interesse, Enrico prontamente se ofereceu para me acompanhar e me apresentar em certos locais. Seu corpo de homem, branco, italiano, idoso, foi um grande diferencial para meu acesso a tais locais - até então "problemáticos" de serem frequentados por mim. Uma experiência interessante que diz muito sobre meu corpo racializado se deu, justamente, no momento em que me apresentava a Enrico. Ao estender-lhe a mão, ouvi dele o seguinte comentário: "Sua mão é delicada, parece mão de europeia". Certamente ele pensou que estava fazendo

\footnotetext{
${ }^{2} \mathrm{O}$ corpo da mulher brasileira, especialmente negra, foi racializado e sexualizado através de propagandas de turismo, sejam nacionais ou internacionais. Essa imagem da brasileira como prostituta é muito recorrente no imaginário coletivo europeu.

${ }^{3}$ Sendo o principal objeto da pesquisa de mestrado a imigração e a insegurança, e se os imigrantes incorporam essa representação sobre eles, foi importante recolher os discursos no bairro sobre os imigrantes mais ligados a essas imagens, como dito, às zonas indicadas como "inseguras" e "perigosas". Para isso precisei circular no bairro dia e noite, frequentar esses espaços e conversar com diferentes grupos de imigrantes, sobretudo aqueles indicados como causa do problema de segurança.
} 
um elogio ao me comparar à mulher europeia, e que isso me deixaria feliz; contudo, sua frase demonstra o racismo naturalizado e o quanto o corpo da mulher negra é visto como inferior, rude e grosseiro em comparação à mulher branca europeia. Aproximá-la do ideal branco, europeu, de traços finos e supostamente delicados seria exaltá-la e tirá-la dessa condição "maltratada" de primitiva e selvagem. Questionei o "elogio" dizendo: "Mas não posso ter as mãos de africana ou brasileira pra serem delicadas?”. Um tanto constrangido pela minha reação e nenhuma apreciação frente à comparação, ele tentou se reparar: "sim, é verdade, as mulheres senegalesas têm os traços delicados".

Por outro lado, uma nova dificuldade surgiria devido à companhia de Enrico. Certa vez, conheci um grupo de brasileiros e um deles me revelou que já há algum tempo me via andar pelo bairro com este senhor, concluindo que se tratava de uma prostituta brasileira pronta a "dar o golpe" em um europeu idoso. Essa era a imagem que meu corpo, na companhia de Enrico, transmitia a algumas pessoas, incluindo os próprios imigrantes.

Assim, ao contrário de Sayad (2002), por exemplo, que realizou um trabalho de campo com argelinos na França e teve livre acesso aos alojamentos masculinos, sendo-lhe permitido conversar com os imigrantes e fotografar os espaços, meu corpo de mulher não me permitia isso ${ }^{4}$. A presença de um "corpo estranho" ${ }^{5}$, um corpo feminino, alteraria a rotina, as falas e o acesso à realidade, diferentemente de um "igual", homem e argelino, como no caso de Sayad em sua pesquisa com seus conacionais. Tampouco fui convidada a conhecer os alojamentos de imigrantes no bairro (o que era desejável de minha parte), e pude perceber uma grande resistência da parte dos homens imigrantes com quem conversei. Neste contexto, essa pesquisa também me propiciou a percepção dos limites e possibilidades que um pesquisador pode ter a partir do seu corpo, homem ou mulher, branco ou negro, europeu ou "não europeu".

De fato, as entrevistas com os homens foram muito mais difíceis de serem realizadas do que com as mulheres, principalmente quando as histórias ouvidas e relatadas eram permeadas por sofrimento e humilhação. A tendência dos homens era minimizar os fatos trágicos, fazer brincadeiras, desviar o assunto (assim como o olhar), pois demonstrar fraqueza - ser historicamente construído como mais frágil - diante de uma mulher causa constrangimento e vergonha. É um comportamento construído pelas sociedades patriarcais, nas

\footnotetext{
${ }^{4}$ Com um corpo de mulher, e devido a toda uma "construção social" da mulher brasileira, o acesso aos homens era um obstáculo para as entrevistas, principalmente em relação aos que não eram apresentados a mim por outras pessoas, mas que eu precisei abordar nas ruas, em estabelecimentos, etc. Ao mesmo tempo, enquanto mulher, tive fácil acesso ao contato com outras mulheres, inclusive às suas casas.

${ }^{5}$ Tal "estranheza" vem do fato de ser um corpo de mulher inserido em um alojamento predominantemente masculino.
} 
quais o homem representa o detentor exclusivo da "força" e do "controle" das relações sociais. Ainda que isso não fosse verbalmente explícito, essa situação pode ser percebida a partir da maneira de homens e mulheres se posicionarem durante as entrevistas. A tendência dos homens de minimizar a questão ocorria principalmente através de expressões semelhantes a que recorriam ("Deixa pra lá"; "Isso é outra história"; "Vamos mudar de assunto").

Neste contexto social de Veronetta, um caso interessante ocorreu com um dos entrevistados, um albanês que dormia no local de trabalho e que, no início da sua chegada à Itália, vivera nas ruas por alguns anos. Após várias conversas em que relutava relatar os detalhes mais difíceis de sua vida, certo dia ele finalmente "se abriu". No dia seguinte, fui convidada por ele para um café e ele fez questão de pagar a conta. Seu entusiasmo era tanto que insistia em dizer que era frequentador assíduo do local, e que a proprietária era uma grande amiga sua.

O caso mais emblemático dessa questão, porém, se refere a três moradores de rua, originários da Romênia, que encontrei em Veronetta ao amanhecer de um dia frio. A cidade ainda dormia e, enquanto eles arrumavam suas "camas", me aproximei, fiz uma breve apresentação e perguntei se poderia oferecer um café aos três. Durante a conversa, eles faziam questão de evidenciar sua dignidade, afirmando por diversas vezes que trabalhavam antes de morar na rua, tinham casa no bairro e eram homens "de bem". Sendo aquele exato dia um feriado religioso, um deles insistia em mostrar que conhecia as festas e os santos das igrejas católica e ortodoxa. Após alguns dias, me deparei com dois deles procurando comida diretamente no lixo perto de onde eu me hospedava. Ao me verem, ambos abaixaram suas cabeças, constrangidos e humilhados porque eu os havia flagrado em tal situação. Diante daquela cena, optei por cumprimentá-los, mostrando que não eram "invisíveis" ou indiferentes para mim. Aproximei-me, toquei no ombro de um deles e disse "bom dia", mas, ainda assim, a resposta foi dada de cabeça baixa e em tom de desconcerto.

O que Haraway (1995) critica na tradição científica masculina, sobretudo positivista é, pois, o fato dos homens dificilmente se situarem como corpo, ao mesmo tempo em que as experiências que envolvem o corpo das mulheres vão sendo deslegitimadas, especificamente de mulheres afrodescendentes ou provenientes do Terceiro Mundo. Por isso é permitido a um "homem" pesquisador entrar em alojamentos masculinos, andar à noite sem medo de ser violado nem sofrer "cantadas" durante o trabalho de campo, e talvez considerar essas questões meras "paranoias femininas", uma vez que, dessa forma (e nem sempre fazendo parte de uma "consciência masculina"), todo o saber construído por mulheres fica relegado a uma condição de saber específico, em detrimento de um saber geral e universal que ainda hoje se perpetua como tradição.

Daí a autora enfatizar que as teorias feministas não devem se enquadrar na pretensão de uma "objetividade" que prevê certa "transcendência" do saber, 
de uma história que perca o rastro de suas mediações, mas sim ter consciência de que os saberes são parciais e situados. Assim, para Haraway (1995, p. 12), existem "corpos marcados" e outros que se pensam "não marcados", que "alegam ter o poder de ver sem serem vistos, de representar, escapando à representação". Como pesquisadora, a consciência de ter um corpo "marcado" (e um corpo que era "visto") ${ }^{7}$ acabou por me propiciar uma posição muitas vezes privilegiada em relação a outros corpos "marcados", de imigrantes provenientes de ex-colônias, de mulheres e de não brancos.

O aspecto positivo de ter um "corpo marcado" é que ele me permitiu, por outro lado, a livre circulação por locais frequentados ou administrados por imigrantes sem causar desconfiança. Um exemplo dessa situação ocorreu em um Centro de Imigração que oferecia serviços e consultoria para imigrantes no bairro, na Rua XX de Setembro, onde esperei que o responsável - um senhor do Sri Lanka - terminasse um atendimento para que eu pedisse algumas informações. Durante minha espera, um imigrante chegou e, ao perguntar se eu seria a próxima, respondi que podia passar na minha frente. Aqui, o caso apenas ilustra que meu corpo não alterou a rotina do local, pois eu era vista como mais uma pessoa que também buscava ajuda para problemas relacionados à imigração, devido, justamente, às minhas características físicas e fenotípicas: meu corpo era um corpo "igual", que tinha o "direito" legitimado de estar ali.

Ainda segundo Haraway (1995, p. 19), toda visão sobre determinado fenômeno possui uma "natureza corpórea"8. Além de ter consciência desta "natureza”, minha reflexão durante o trabalho de campo levou em consideração a "antropologia encarnada" de Mari Luz Esteban, cuja proposta é de uma "interconexão entre experiência corporal própria (...) uma autoanálise acerca da própria experiência corporal e o estudo acerca das interações sociais." (ESTEBAN, 2004, p. 2-3) ${ }^{9}$

É interessante ressaltar que, no entendimento da "antropologia encarnada", o pesquisador não só observa o outro, mas também se observa o tempo todo durante o trabalho de campo. Através dessa abordagem, foi de suma importância

\footnotetext{
6 "Corpos marcados" é um conceito fundamental utilizado por Haraway.

${ }^{7}$ Como no referido caso em que um brasileiro confessou ver-me no papel de uma prostituta em busca de vantagens financeiras na Itália, ou quando outros imigrantes se mostravam confusos com o meu objetivo no bairro, pois meu corpo remetia a uma imagem construída (mulher latino-americana, e para alguns, prostituta brasileira) enquanto eu me apresentava como uma pesquisadora.

8 "Natureza corpórea" ta mbém é um conceito de Haraway.

${ }^{9}$ Tradução livre. No original (passagem completa): "Este hacer consciente esplicita la interconexión entre la experiencia corporal propria y la investigación al que voy a referirme a continuación, lo resumo en el término "antropologia encarnada", mediante el que pretendo reinvindicar un ejercicio antropologico que tenga en cuenta la doble dimensión: auto-observación con el análisis desde el concepto de embodiment."
} 
para minhas reflexões perceber o que certos discursos significavam não apenas para outros imigrantes, mas também o que provocavam em mim. Aqui, os exemplos vão desde situações de racismo presenciadas dentro de ônibus coletivos, um comentário de uma enfermeira em um hospital e uma cena de racismo e xenofobia em um local frequentado majoritariamente por italianos, até discursos de ódio por parte de imigrantes brasileiros do sul contra os nordestinos.

Ao enfatizar o "poder do físico", Esteban aponta como homens e mulheres são agentes sociais através dos seus corpos: o corpo na sociedade contemporânea capitalista "é o lugar da discriminação, mas também de empoderamento" (ESTEBAN, 2004, p. 13) ${ }^{10}$. Por isso também minha inserção no campo, através de um "corpo marcado", constituiu um aspecto facilitador. Como exemplo, posso relatar uma visita feita à casa de uma das entrevistadas de origem marroquina, e que disse a seus filhos (se referindo a mim): "Olha o seu rosto. É uma de nós". Ou ainda na casa de Ernesto, outro imigrante, quando me dirigi a Baidy, um rapaz senegalês, dizendo que eu era brasileira, e obtive o seguinte comentário: "Então posso falar tudo?" Ao responder que sim, que poderia dizer tudo aquilo o que desejasse na entrevista, uma grande risada coletiva tomou conta da casa (nesse momento, o grupo era formado por brasileiras, guineenses e um senegalês). ${ }^{11}$

Outras situações semelhantes a essas se apresentaram durante meus almoços com Oxana, uma senhora romena que tratava os imigrantes por "nós" (me incluindo nessa condição), enquanto os italianos por "eles". Uma das frases mais proferidas por Oxana era "Mas você me entende!", o que evidenciava mais fortemente que me considerava como semelhante. Outra experiência interessante ocorreu com Mirian, uma senhora mexicana que eu havia conhecido através de uma imigrante brasileira em Veronetta. Certa vez, por volta do meio-dia, ela me ligou perguntando se eu gostaria de ir a sua casa para uma entrevista, e também para almoçar. Quando cheguei, ela revelou que, se eu fosse italiana, não teria me convidado em cima da hora, porque isso não se faz “com eles". Além disso, após eu ter revelado que o fogão do meu quarto não funcionava, ela gentilmente me ofereceu sua cozinha durante minha estadia na Itália.

Esta espécie de aproximação com a condição de imigrante a partir do meu corpo e a minha similaridade com muitos deles também foi um fator contraditório na pesquisa de campo. Ao mesmo tempo em que me permitiu circular

\footnotetext{
${ }^{10}$ Tradução livre. No original: "El corpo es un lugar de discriminaciòn però también de resistencia y de contestaciòn."

${ }^{11}$ Considero que entrevistas com os autóctones teriam apresentado mais limitações do que com os imigrantes, uma vez que seria uma "outra" pedindo a eles para falar de "mim" (meu grupo). O acesso aos imigrantes como uma "igual" ou "símile”, como muitos me reconheceram, facilitou o diálogo, ao mesmo tempo em que puderam falar "deles” (os italianos) com maior abertura, pois eu não fazia parte da sociedade a ser descrita, criticada ou elogiada.
} 
em algumas realidades, me dificultou em outras situações, pois o fato de ser uma mulher negra, brasileira e latino-americana - traços explícitos de que eu não era europeia - fez com que alguns imigrantes "duvidassem" do meu trabalho como pesquisadora. Em outra ocasião, na presença de homens, um deles expressou "hoje você parece pesquisadora", referindo-se às minhas mãos abarrotadas de livros e pastas. Também não faltaram perguntas dos proprietários das lojas do bairro sobre a veracidade do meu trabalho, tais como: "Quem te mandou aqui?" ou "ah, mas sua pesquisa então é para o Brasil?".

Essa hierarquia dos corpos, criada com a racialização de povos a partir da colonização, é algo presente nas mentalidades de forma geral. O corpo de um "símile" pode aproximar pessoas e pode também causar suspeitas, rejeição, desconfiança sobre o lugar do outro - neste caso, pesquisadora, e não subalterna naquele momento específico.

É Wacquant (2006) quem nos lembra que Bourdieu foi um grande etnógrafo na tradição sociológica, pois seus trabalhos de campo contribuíram significativamente para a teoria social contemporânea. Seus primeiros estudos sobre a Cabila na Argélia e em Béarn, sua terra natal no sudoeste da França, trazem importantes elementos de reflexão para um pesquisador em campo na atualidade, sobretudo porque não exime de estudar a si mesmo enquanto estuda a realidade. Como afirma Wacquant (2006: 1), quando Bourdieu decide "voltar às suas origens" através do estudo de campo em sua aldeia de infância, percebe que pode "traduzir sua inquietação existencial em relação à 'postura escolástica' - inquietação enraizada em suas disposições anti-intelectualistas herdadas de sua criação numa classe e nunca posição etnorregional subordinada". A consciência de "pertencimento" que Bourdieu traz para o campo, e que orientou sua postura, seus questionamentos e sua sensibilidade ao olhar para este fenômeno, então, ajudaram-me a perceber também o meu próprio lugar, o lugar de onde "vejo" a realidade - o que ele chama de "objetivação da subjetividade":

Conhece-se melhor o mundo à medida que melhor conhecemos a nós mesmos, uma vez que o conhecimento científico, nosso autoconhecimento e da nossa própria inconsciência social avançam de mãos dadas, e a experiência primária transformada em e através da prática científica modifica a prática científica. (BOURDIEU, 2003, p. 298)

Essa consciência de "pertencimento" a um lugar dado de antemão e "denunciado" pelo meu corpo foi algo que se revelou aos poucos na pesquisa. Neste sentido, sabemos que Bourdieu percebe sua posição de classe e posição regional e, em outras obras (como em A dominação masculina, de 1998), até sua posição de homem. No entanto, o autor não discorre sobre seu próprio corpo, o que a socióloga Felly Nkweto Simmonds considera privilégio de um homem 
branco. Para ela, mulher e negra, sua subjetividade é chamada a todo instante no seu fazer ciência. E como "outra", ela se percebe assim porque o mundo é branco. Daí, no caso dos homens brancos, ser difícil para eles se perceberem como são no mundo, porque este mundo os reflete, sendo difícil tomar consciência disso. A autora assim expressa sua condição de socióloga negra:

Eu quero argumentar que uma compreensão intelectual da realidade social não é suficiente, e que essa compreensão da realidade social não é suficiente e que tal compreensão deve examinar criticamente a relação entre as realidades individuais/pessoais e coletivas/sociais. Neste mundo branco eu sou um peixe de água doce que nada na água do mar. Sinto o peso da água... no meu corpo. (SIMMONDS, 1999, p. 51)

Para Simmonds, não é possível ignorar o fato de ser negra, de ter um corpo racializado, por mais que ela queira.

Para alguns de nós é impossível escapar do corpo e suas construções, mesmo dentro da "máquina de ensino". Esperam de mim que eu não apenas carregue meu corpo, mas reconheça isso. Tenho um relacionamento específico e claro com o conhecimento que ensino, através do meu corpo. A contradição para mim é que, embora eu possa claramente ser convidada a falar sobre questões de "raça", é somente quando escolho falar sobre as experiências da racialização do meu corpo que minha autoridade para fazer isso é questionada ou descartada como subjetivo e "confessional". Esperam de mim ser, mas não saber sobre ser. (SIMMONDS, 1999, p. 52$)^{13}$

A autora cita uma fala de Bourdieu em que diz não falar de si, da vida pri-

\footnotetext{
12 Tradução livre. No original: "I want to argue that an intellectual understanding of social reality is not enough, and that such an understanding of social reality is not enough, and that such understanding has to critically examine the relationship between individual/personal and collective/social realities. In this white world I am a fresh water fish that swims in sea water. I feel the weight of the water... on my body."

${ }^{13}$ Tradução livre. Grifo nosso. No original: "For some of us, it is impossible to escape the body and its constructions, even inside the "teaching machine". I a m expected to not only carry my body, but to acknowledge it. I have a specific and clear relationship to the knowledge that I teach, through my body. The contradiction for me is that, whereas I can clearly be invited to speak about "race" issues, it is only when I choose to speak about the experiences of the racialization of my body, that my authority to do this is questioned or dismissed as subjective and "confessional". I'm expected to be, but not to know about being."
} 
vada, das preferências, pois para o sociólogo seria dar munição para as pessoas que jogam veneno contra os sociólogos, alegando o relativismo deles. A autora definirá isso abertamente como "luxúria" (sobre o privilégio de não precisar falar de si ou não ser chamado em causa para isso). Essa "descorporificação" de alguns seria uma situação privilegiada que, para mulheres negras, não é possível. E, ainda que de forma diferente, nem mesmo as mulheres brancas "escapam" desse saber corporificado, por imposição ou por consciência disso. Pois, muitas vezes, as mulheres trouxeram para o debate sobre as questões ligadas à sua condição de ser mulher, ao corpo, às questões que só o universo feminino enfrenta, então, as mesmas que são taxadas de "passionais", subjetivistas, e contribuidoras para uma ciência falha.

Também a "antropologia encarnada" de Esteban (2004, p. 2) enfatiza o "vínculo entre vida e processo de investigação". Como antropóloga e pesquisadora do corpo, a autora conta a própria experiência de ter passado por uma doença - foi gravemente obesa por um longo período de sua vida - e ter visto, por exemplo, a dramática transformação física pela qual passara (que incluía agravantes como o crescimento de pelos no rosto). Ela reivindica o exercício de auto-observação e de "partir de si mesma", isto é, da própria experiência, para entender melhor o outro, principalmente quando o pesquisador já passou pelas mesmas coisas que o(a) outro(a) pesquisador(a). Por outro lado, partir da própria experiência ou expô-la em trabalhos científicos, de acordo com a antropóloga, ainda é um procedimento que causa muito incômodo entre os cientistas, resultando em um exercício difícil, e nunca um mero prazer de exposição pessoal.

A "autoantropologia" de Esteban (2004 p. 16) encontra resistências devido à tradição positivista nas Ciências Sociais e ao status dado à objetividade e à distância entre o investigador e o objeto investigado. Por isso ela diz não abrir mão de reconhecer o "valor da experiência pessoal", do "subjetivo" na prática científica e acadêmica, uma vez que a própria experiência é "fonte de conhecimento" (ESTEBAN, 2004, p. 17). Além disso, é um exercício da tradição feminista pelo qual ainda é preciso lutar para ser reconhecido como elemento constituinte da teoria social. Para a autora, se trata de uma estratégia única que liga conteúdos e interpretações da experiência inacessíveis de outra forma, além de contribuir com a teoria social e a metodologia, uma vez que as leva a uma revisão crítica profunda dentro das disciplinas e das Ciências Sociais em geral.

Obviamente, a experiência sozinha e isolada não produz pensamento ou teoria social, sendo necessário que haja, entre outros aspectos, as passagens cruciais como a "objetivação da subjetividade" apontada por Bourdieu (2003). Olhar para minha experiência anterior como imigrante depois de alguns anos, e não mais nessa condição, neste sentido, foi e continua sendo também uma experiência de ressignificação. A seguir, relato alguns episódios dos anos ante- 
cedentes, na condição de imigrante brasileira na Itália (em particular na cidade de Verona), que me aproximaram do tema estudado, além de terem contribuído para a escolha do campo e da metodologia, e que, enfim, facilita muito meu trabalho etnográfico, bem como o contato com os entrevistados.

\section{"Autoetnografia": um breve relato da minha experiência como imigrante na Itália entre os anos de 2008 e 2014}

A "autoetnografia" na obra de Esteban (2014), como o nome já diz, se dá quando o pesquisador não se exime de analisar a própria experiência e as interconexões da própria vida com o tema estudado. No seu caso, o tema do corpo como objeto de estudo ganhou uma considerável autoanálise que levou em consideração sua condição de mulher, como dito, com uma doença que a colocava em uma situação de "corpo não reconhecido" ou "corpo marcado" no interior da sociedade espanhola na qual nasceu (e ainda vive). Ter passado por essa experiência e analisá-la, do ponto de vista do tema do corpo, foi um grande diferencial em sua pesquisa.

Como antropóloga e feminista, Esteban aponta a importância de se situar diante do objeto de pesquisa e do relato da própria experiência como marca da posição feminista dentro das Ciências Sociais, pois a tradição masculina tende a se eximir de falar de si estabelecendo uma separação radical entre o âmbito público e o privado, entre o eu e o outro, e, enfim, entre o objeto estudado e o pesquisador. A experiência pessoal relatada e situada em ambos, pesquisa e pesquisador, ajuda a entender as interconexões entre as esferas dicotômicas criadas pela tradição masculina positivista, supostamente impessoal e acrítica. É nesse sentido que considero importante um breve relato da minha condição de imigrante na Itália, previamente a esta pesquisa, por um período de seis anos (de 2008 a 2014).

Minha experiência anterior como imigrante me permitiu, em campo, atuar com uma postura de quem já viveu algumas situações típicas da condição de imigrante que, segundo o olhar que retenho, diferem principalmente daquelas mulheres que nunca as presenciaram, a exemplo da experiência de muitas latino-americanas que são barradas em aeroportos internacionais. Quando fui para a Itália em 2008, com escala aérea na França, fui barrada no Aeroporto de Paris Charles de Gaulle por policiais que selecionam, inicialmente pela aparência física, aqueles que julgam dever ser investigados sobre os motivos da entrada no país. Após ter minhas malas revistadas, uma estátua de gesso quebrada e o computador também "revistado", fui retida para um longo interrogatório, após o qual finalmente consegui embarcar para a Itália (tendo perdido minha conexão anterior na França). Em solo italiano, novamente minhas malas foram revistadas (incluindo os frascos de xampus, que foram abertos, e coisas assim) e mais uma vez fui submetida a um longo e constrangedor inter- 
rogatório, cujas perguntas íntimas tinham o claro intuito de saber se eu estava indo para a Itália para me prostituir.

A mesma experiência de ser detida em um aeroporto europeu nos relata Patrícia Rangel (2012), como parte de reflexões sobre raça e gênero na coletânea Viajante, pesquisadora, convidada... ou não: mulher latina em trânsito, sobre migração e globalização. ${ }^{14}$ Seu relato de mulher, brasileira e latino-americana, pode ser considerado uma "autoetnografia" nos termos semelhantes de Esteban como dito, típica da tradição de mulheres que tentam religar a dimensão pessoal à teoria social sem cair no subjetivismo estéril. Rangel conta que embarcou para a Europa para participar de um congresso em Portugal e, ao realizar escala na Espanha, ficou detida por quatro dias no Aeroporto de Madri injusta e ilegalmente, já que trazia consigo todos os documentos necessários para prosseguir sua viagem a Lisboa: o passaporte válido, dinheiro, o comprovante de que iria participar do congresso em questão e o agendamento no hotel aonde iria se hospedar. Sendo inúteis suas explicações, segundo a autora, a indignação pela prisão arbitrária passou a reforçar um estado de extrema fragilidade, pois nem mesmo à justiça ela podia recorrer, uma vez que as autoridades espanholas haviam retirado dela qualquer direito. Durante sua prisão ela relata o que caracteriza um "estado de exceção", onde seu silêncio e submissão lhe eram lembrados a todo instante como únicos comportamentos aceitáveis. ${ }^{15}$

Particularmente, minha "condição de imigrante" na Itália não se deu por uma escolha pessoal, pois se sentir ou não "imigrante" não é uma questão de escolha, mas, sim, de um posicionamento imposto pela sociedade. Antes mesmo que eu chegasse à Itália, através de meu namorado, tive a informação de que um casal de amigos seus havia me oferecido um emprego como faxineira na casa deles. Quando soube disso, não pude conter a minha indignação, não pelo trabalho em si (temporário, até que o filho do casal nascesse), mas pelo fato de que eu já tinha um lugar determinado no imaginário deles e não cabia sequer a possibilidade de que eu pudesse fazer outro tipo de atividade, como, por exemplo, prosseguir com meus estudos acadêmicos. E não me faltaram

\footnotetext{
${ }^{14} \mathrm{O}$ relato da sua prisão em Madri dentro de uma coletânea sobre o tema da imigração é de imensa coragem e revela uma postura crítica singular, pois enquanto outros(as) autores(as) enfatizam a "objetividade" de estudos os mais diversos, Rangel reporta a própria experiência como objeto de estudo e análise.

${ }^{15}$ A securitização opera uma ruptura com as normas políticas, pois implica na prioridade dada às decisões das lideranças em detrimento da participação e do direito popular. A preocupação com um constante "estado de exceções" na Europa é legítima, uma vez que faz parte da política "securitária" que aumenta o poder do Estado. O filósofo italia no Giorgio Agamben, cuja obra aborda contemporaneamente o "estado de exceção", ressalta a preocupação com esse processo; segundo ele, dentro do Sistema Estado-Nação os direitos humanos "mostram-se desprovidos de qualquer tutela no instante em que não seja possível configurá-los como direitos dos cidadãos de um Estado.” (AGAMBEN, 2010, p. 123).
} 
propostas de empregos como diarista, ou de pessoas surpresas pelo fato de eu não estar buscando trabalho naquele momento.

Frequentei por dois anos um curso de italiano para imigrantes regulares oferecido pela Prefeitura de Verona no ano em que cheguei à Itália, e conheci muitas pessoas de diferentes nacionalidades, todas elas de países em desenvolvimento. Isso também diz muito sobre ser imigrante, pois em outra ocasião, quando procurei um curso de língua italiana particular para acelerar meu aprendizado, me deparei com uma escola no centro da cidade frequentado, em grande parte, por europeus do norte da Europa e de outros países ricos (França, Holanda, Estados Unidos, Japão), além de pessoas oriundas de países em desenvolvimento que, por seu lado, faziam parte de uma elite no país de origem (a exemplo da China).

Essa experiência como imigrante durante seis anos em Verona foi fundamental para minha inserção no campo e para o contato com o "mundo" dos imigrantes. Essa experiência também foi fundamental para a seleção do bairro para a etnografia, pois de início eu o frequentava para comprar os produtos brasileiros que me faziam falta no dia a dia, e só depois o fiz como estudante do mestrado na universidade situada ali (e ainda como estagiária numa associação da Prefeitura para mulheres imigrantes, a Casa di Ramia, também em Veronetta).

Fui também voluntária no curso de verão para crianças imigrantes em 2011 no Centro de Estudos sobre Imigração (CESTIM). Neste, conheci e convivi com muitos pais e pude ver suas dificuldades em acompanhar os estudos dos filhos na escola, principalmente no auxílio às tarefas de casa - tanto que assumi o compromisso de ajudar uma família de senegaleses com duas filhas no ensino fundamental. Em 2013, também visitei a Caritas Verona, que acolheu diversos refugiados políticos, ato esse que nasceu da indignação das manifestações de autóctones, em frente à entidade, para que os refugiados fossem expulsos de lá. Cheguei a acolher em minha casa uma família de nigerianos (mãe, pai e filha) que trabalhavam na Líbia e que, depois da guerra, chegaram à Itália por meio de uma precária embarcação através do Mar Mediterrâneo.

Essa experiência anterior me permitiu ir a campo tendo consciência de certas coisas que não são abertamente ditas na Itália, mas compartilhadas por todos, principalmente detalhes que só a vivência pode oferecer, e que esses meses de campo não seriam suficientes para tal compreensão. Por exemplo, ao chegar em Verona com meu filho no dia 5 dezembro de 2015, para realizar essa pesquisa, minha sogra italiana me disse - logo que chegamos a sua casa, ainda que um tanto quanto constrangida - que gostaria de presentear meu filho com um novo casaco de frio, pois ele se assemelhava a um "bambino" (menino) do Kosovo devido a suas vestimentas. Tal colocação não teria o mínimo sentido para mim se eu não soubesse que o modo de vestir para os italianos, ao 
menos daquela região ${ }^{16}$, é um modo de distinção de classe e de outros "povos" também - no caso, os imigrantes. Afirmar que ele parecia um "menino do Kosovo" era dizer que estava malvestido, pois seu casaco marrom e velho lhe remetia à ideia da pobreza de crianças do leste europeu, o que, segundo ela, poderia causar constrangimento para ele e para toda a família.

Meu domínio da língua italiana também propiciou um diferencial em minha pesquisa, não só a ponto de facilitar minha comunicação, mas por me permitir entender certas sutilezas da linguagem que fazem diferença nas relações pessoais. Por exemplo, na Itália existem dois tipos de pronomes pessoais para se dirigir a uma pessoa: o "tu" e o "Lei". ${ }^{17}$ Em algumas entrevistas, percebi que alguns imigrantes faziam questão de estabelecer a relação a partir de "Lei" (como um empresário do Marrocos, homem de uma classe social privilegiada) que é sinal de respeito, mas também de distância com o interlocutor. Por outro lado, duas entrevistadas mencionam a falta do uso do "Lei" pelos italianos para se dirigirem aos imigrantes, mostrando-se indignadas por presenciar italianos que se dirigiam a imigrantes com o pronome "tu", que, para elas, é sinônimo de desrespeito, uma vez que os italianos pretendem, no caso de um desconhecido se dirigir a eles, ser tratados com o pronome "Lei".

Uma experiência comum para a condição de imigrante é a passagem pelo longo e tortuoso caminho para obter o visto no órgão da polícia de cada cidade. Quando cheguei em Verona, a fila para a legalização dos documentos em frente ao prédio da polícia local começava a se formar já na noite anterior, pois a cada dia apenas algumas senhas eram distribuídas, a partir das 8 horas da manhã, quando os portões se abriam. Nessa fila era possível encontrar homens e mulheres, idosos, crianças (inclusive de colo), pessoas com deficiência, grávidas, todos eles submetidos ao tratamento desumano de permanecer em pé ou sentados no chão, geralmente a noite inteira, por vezes com o agravante das estações mais frias (durante o inverno, a cidade já chegou a assinalar $15^{\circ}$ Celsius negativos). Na terceira vez em que fui renovar meu visto, estava grávida de sete meses e cheguei às 4 horas da manhã para tentar conseguir uma senha. Quando o portão se abriu, perguntei a um policial se poderia obter um atendimento prioritário para grávidas e, diante do meu pedido, ele apenas questionou friamente: "Você tem algum comprovante de que está grávida?" Para ele, uma barriga de sete meses não era prova suficiente de minha gravidez, e eu fui obrigada a permanecer na fila.

Certa vez, tomava meu rotineiro cappuccino pela manhã em um café, sozinha, e pude ouvir a proprietária, em tom de desabafo e com voz raivosa,

\footnotetext{
${ }^{16}$ Vestir-se bem é também um modo de se inserir e se livrar do estigma da imigração, combinando cores e roupas de marca dentro do que na Itália é chamado de "senso estético Italiano". ${ }^{17}$ Ambos significam "você", mas "Lei" (sempre grafado com inicial maiúscula) é um termo mais formal, distante e respeitoso.
} 
se dirigindo a um grupo de senhoras italianas, todas idosas, dizendo: "Essas mulheres imigrantes têm até o sapato melhor que o meu". Incrédula com o comentário, dirigi-me a ela e a questionei sobre aquilo que acabara de dizer. Sem contar com a minha reação, ela se justificou afirmando que se referia às africanas que, segundo ela, vêm para a Itália, não trabalham, vivem à custa de assistencialismo e ainda fazem muitos filhos.

Durante toda a pesquisa não recebi com espanto as falas e as experiências relatadas pelos imigrantes, porque durante meu próprio período como imigrante ouvi e vivenciei várias situações semelhantes. Tampouco tentei minimizar experiências de sofrimento, reação esta que se mostrou algo de muito positivo para os imigrantes entrevistados. Por exemplo, quando entrevistei o mexicano Carlos, ele me pedia que falasse com sua irmã (que estava a mais tempo na Itália) nos seguintes termos: "Ela precisa falar com você, ela não está bem”. Carlos havia relatado uma experiência sua de discriminação em um consultório médico, experiência essa de explícito senso de superioridade do médico em relação a ele, junto a comentários depreciativos em relação ao México. Ao contar esse episódio a um italiano, ouvi a seguinte frase: "E você acredita em tudo que dizem? Pra mim parece um pouco exagerado”. A postura de desacreditar os imigrantes e minimizar o sofrimento deles é típica do comportamento colonialista dos europeus com relação ao resto do mundo, principalmente frente às pessoas oriundas de países pobres. Carlos não devia estar exagerando, pois o que lhe aconteceu é comum para muitos imigrantes. Para estes, enfim, sentir que alguém não os desacreditava - enquanto leva em consideração a carga de sofrimento imposta a eles - era de suma importância para a confiança e a abertura nos diálogos.

Dias antes de retornar para o Brasil, uma conversa com a marroquina Houda também mostrou o quanto o fato de ouvi-los, e de não colocar em dúvida suas experiências, foi fundamental. Ela já havia me concedido uma entrevista e eu a havia encontrado em outras ocasiões. Neste dia, porém, ela me perguntou: "Você sabe da última?" e, ao meu sinal de atenção para ouvi-la, relatou o fato de haver na escola de seu filho uma matéria facultativa de ensino religioso, na qual pais muçulmanos, por exemplo, podem optar em deixar os filhos participar ou não das aulas. E duas mães muçulmanas indignadas a procuraram para saber se seu filho, durante a ausência em tais aulas, também limpava os banheiros da escola. Houda, mãe muçulmana que faz questão de que seu filho participe das aulas e se engaje nos debates, na tentativa de desconstruir muitos preconceitos sobre o Islã, respondeu que não, e então as mães contaram que, como atividade "alternativa" à aula de religião, suas filhas eram obrigadas a limpar banheiros. Procuraram a diretora da escola, que disse desconhecer o fato; porém, em reunião com os pais a professora responsável confirmou o ocorrido e pediu desculpas às famílias, dizendo apenas que o fato não volta- 
ria a acontecer. ${ }^{18}$ Houda não teria me contado essa última experiência se não tivesse certeza de que eu daria a importância que o episódio merece e não buscaria de nenhuma forma minimizar o ocorrido. Minha experiência como imigrante me mostrou que não existem exageros nesses tipos de experiências.

\section{Considerações Finais}

Pensar os desafios de campo a partir do corpo e dos seus lugares nas sociedades é importante para a "reconciliação" entre os dualismos criados pela tradição científica masculina e ocidental. Não apenas isso, é também dar legitimidade às experiências de corpos "marcados" que são anuladas, bem como muitas vezes relegadas ao "limbo acadêmico", acusadas de pseudociência e de subjetivismo infundado. Contudo, não se trata de um mero prazer de falar de si e de expor-se, mas de perceber as interconexões entre história individual, corporeidade e história social.

Com as experiências relatadas durante a pesquisa de campo no mestrado, propus-me somar forças com muitas outras mulheres pesquisadoras que ainda precisam lutar contra abusos, assédios e até a falta de credibilidade devido ao fato de possuírem um corpo sexuado ou mesmo racializado. Mas tal luta também aponta formas criativas que emanam da própria experiência feminina para obter confiança, acesso a locais e outras "conquistas" que contribuem, assim, para o avanço das pesquisas de campo. O corpo é o principal elemento de interação: chegando antes de qualquer coisa, é a primeira mensagem a ser transmitida. Com base nele, portas podem ou não ser abertas. Portanto, a partir dele se busca aprofundar ou não o nível das relações, muitas vezes iniciada a partir de estereótipos. E quando se trata de entrevistar, participar e observar uma realidade, é fundamental tomar consciência de haver um corpo e, no caso de muitas mulheres, um "corpo marcado".

Quando decidi realizar a pesquisa na Itália e delimitei o campo, eu estava consciente de que meu acesso aos italianos seria mais difícil do que aos imigrantes, e pude entrever isso devido à minha experiência prévia como imigrante, pois com a convivência fui percebendo que grande parte da população local me via como inferior. Não que os imigrantes não tenham seus preconceitos e estereótipos com seus semelhantes, mas muitas vezes é mais fácil falar do racismo do outro do que do próprio quando se é indagado. Meu corpo, para os italianos em geral, seria um elemento de "desconforto" se quisessem dizer tudo aquilo que pensam sobre o outro imigrante, uma vez que, neste caso, eu estaria incluída. Pois quando Haraway diz que todo saber é corporificado, esse

\footnotetext{
${ }^{18}$ Houda contou que os pais italianos ainda ficaram revoltados com essas duas mães e as isolaram, alegando que elas criaram um problema desnecessário.
} 
meu "recorte" também o é (entrevistar imigrantes e não os italianos).

A experiência de Rangel no aeroporto de Madri e sua reflexão sobre o lugar da mulher latino-americana no mundo é uma das grandes contribuições para que seja desconstruído o mito de que todos e todas podem pesquisar tudo e sobre todas as coisas. Existem "corpos" que não têm acesso a pessoas e a lugares, e isso não é uma questão de escolha ou simplesmente de mérito pessoal. Aqui a autoetnografia proposta por Esteban ajuda a nos situar, visto apoiar as experiências de mulheres que não sabem onde colocar a própria vivência corpórea dentro da pesquisa e do fazer ciência. E ajuda muitos homens a questionar a naturalidade do lugar de fala e dos seus corpos.

\section{Referencias Bibliográficas}

AGAMBEN, Giorgio. Homo Sacer: o poder soberano e a vida nua I. Tradução de Henrique Burigo. Belo Horizonte: Editora da UFMG, 2010.

ESTEBAN, Mari Luz. Antropología Encarnada. Antropología desde una misma. Papeles del CEIC 12, jun, 2004. Disponível em: http//ehu.es/CEIC/ papeles/12.pdf (acesso em 30/9/2015).

HARAWAY, Dona. Saberes localizados: a questão da Ciência para o feminismo e o privilégio da perspectiva parcial. Cadernos Pagu (5), pp. 07-41, 1995.

. "Manifesto Ciborgue: ciência, tecnologia e feminismo-socialista no final do século XX”. In: HARAWAY, Donna; KUNZRU, Hari; DA SILVA, Tomaz. (Org.). Antropologia do Ciborgue: as vertigens do pós-humano. Belo Horizonte: Autêntica Editora, 2000.

MALINOWSKI, Bronislaw. Argonautas do pacifico ocidental: Um relato do empreendimento e da aventura dos nativos nos arquipélagos da Nova Guiné, Melanésia. São Paulo: Abril Cultural, 1976.

RAGEL, Patrícia Duarte. "Viajante, pesquisadora, convidada... ou não: mulher latina em trânsito". In: Migração e Globalização: um olhar interdisciplinar. Pereira, Gloria M. S.; Pereira, José R. S. (Orgs.). Curitiba: Editora CRV, 2012.

SAYAD, Abdelmalek. Imigração ou os paradoxos da alteridade. São Paulo: Edusp, 1998.

SIMMONDS, Felly Nkweto. "My Body, Myself: How does a Black woman do sociology?”. In:. PRICE, Janet; SHILDRICK, Magrit. (Ed.). Feminist theory and the body. New York: Routledge, 1999.

WACQUANT, Loïc. Seguindo Bourdieu no Campo. Revista de Sociologia e Política, n. 26, Curitiba, 2006. Disponível em: <http://www.scielo.br/scielo.php?script=sci_arttext\&pid=S0104-44782006000100003 . (acesso em 09/05/2015). 
autora Fabiane Cristina Albuquerque

Doutoranda e mestre em Sociologia pelo Programa de Pós- Graduação em Sociologia da Universidade Estadual de Campinas (Unicamp). Graduou-se em Ciências Sociais pela Universidade Federal de Goiás. E-mail: fabcristbr@hotmail.com

Recebido em 08/12/2017 Aceito para publicação em 14/03/2018 